\title{
A Modernização Tecnológica no Setor de Transformação de Plásticos do Brasil
}

Globalização do mercado, atualização tecnológica, gestão empresarial, engenharia simultânea, reengenharia, etc. são hoje termos correntes tanto no meio industrial como no acadêmico do setor de polímeros. Polímeros: Ciência e Tecnologia elaborou a presente matéria a partir de uma entrevista informal com Roberto Camanho, presidente da SOBRACON - Sociedade Brasileira de Comando Numérico e Automação Industrial, que deu uma visão geral sobre o momento atual vivido pelas empresas de transformação de plásticos, e com José Simantob Netto, superintendente do Instituto Nacional do Plástico - INP, que trouxe informações sobre o mais novo projeto daquele órgão para contribuir com as empresas do setor. Camanho, com 12 anos de experiência na área, está à frente de uma instituição que atua como catalisador de novas tecnologias, oferecendo treinamento especializado, realizando pesquisas de mercado, analisando tendências de investimento tecnológico e buscando interação com associações congêneres no exterior. Simantob destaca-se por sua atuação junto ao INP, instituto que tem por objetivo básico "uma indústria do plástico competindo em base tecnológica e utilizando-se de modernas técnicas de gestão, orientadas para o usuário, em termos de qualidade, custo e inovação”.

\section{CONSEQÜÊNCIAS IMEDIATAS DA GLOBALIZAÇÃO}

As fronteiras da concorrência no setor de transformação de plásticos têm se ampliado cada vez mais nos últimos anos em função da globalização de mercado, tornando a competitividade cada vez mais acirrada e essencialmente dependente da modernização. Sendo assim, são inevitáveis os investimentos na atualização gerencial e tecnológica a curto prazo, para que todo o setor se mantenha competitivo dentro do mercado globalizado.

Muitas empresas têm sentido os efeitos dessas mudanças ao observar seu volume de vendas caindo vertiginosamente, pois o produto concorrente possui melhor qualidade a um custo inferior, muitas vezes próximo ao de sua matéria-prima. A abertura do mercado também alterou profundamente a velocidade de lançamento de novos produtos, sobretudo nos setores em que eles devem ocorrer num período de tempo muito curto, como na eletroeletrônica. Para confrontar esta nova situação, deve-se produzir uma peça melhor, num tempo menor, mais barata e com garantia de qualidade. Isto só pode ser conseguido se as empresas tiverem uma estrutura que lhes dê suficiente agilidade e velocidade não apenas para adaptação à nova realidade mas também para otimizar todos os aspectos de produção, através de investimentos em novas técnicas de projetos, de fabricação de ferramentas, etc.
A competitividade de fora alterou toda a estrutura de base das empresas brasileiras, obrigando muitas delas a rever uma série de atitudes em relação a custos e investimentos em tecnologia. Muitas indústrias do setor de transformação de plásticos têm investido na modernização tecnológica de produção, sem entretanto conseguir os resultados esperados, em função de dois fatores. $\mathrm{O}$ primeiro deles refere-se aos investimentos. Sem um constante questionamento de quais são os objetivos da empresa e o que o mercado espera dela, fica extremamente difícil para o empresário definir exatamente de que tecnologias e equipamentos precisa, fato que o torna suscetível de adquirir um equipamento de alta sofisticação tecno- 
lógica, que dificilmente terá plena utilização. Dessa forma, o investimento acaba sendo feito mais por impulso que por um planejamento efetivo. O segundo fator é a análise de custo. Numa época em que as margens de ganho eram extremamente elevadas, não havia realmente necessidade de se medir nem os ganhos, nem tampouco os custos. Hoje, ao contrário, isso deve ser minuciosamente avaliado no âmbito interno da empresa, pois o mercado consumidor é quem dita os preços dos produtos que, em consequiência, devem ser equivalentes aos disponíveis para importação. A partir deste status quo a lucratividade atual fica extremamente dependente das margens de perda decorrentes da ineficiência dos vários aspectos de produção.

Os tradicionais mecanismos protecionistas ainda têm amenizado o efeito da concorrência, entretanto, a tendência a médio e longo prazo é que as pressões político-econômicas mundiais tornem esses mecanismos cada vez menos efetivos, comprometendo a sobrevivência dos setores atualmente protegidos.

\section{PRÉ-REQUISITOS PARA A MODERNIZAÇÃO}

Atualmente, o desenvolvimento de uma nova peça em plástico pode utilizar recursos computacionais sofisticados. Assim, o design pode ser feito utilizando sistemas CAD (Computer Aided Design); a fabricação do molde, por sua vez, com os sistemas CAM (Computer Aided Manufacturing); a simulação do uso do molde através de sistemas CAE (Computer Aided Engineering) e, finalmente, o controle de operação da máquina através de sistemas avançados de moldagem, conhecidos como CNC (Controle Numérico Computacional) . Na medi- da em que todas estas etapas envolvem diferentes setores, como engenharia, ferramentaria, produção, etc., com profissionais possuindo diferentes perfis técnicos, a mudança dos antigos padrões de gestão da empresa se constitui num dos pré-requisitos para a modernização. A organização gerencial e a tecnologia hoje são interdependentes e a integração dos profissionais dos vários setores é fundamental para que tais recursos tecnológicos sofisticados atinjam sua máxima eficiência durante o desenvolvimento de uma nova peça moldada. Além disso, os funcionários devem ter claro em mente qual é a missão da empresa e se envolver com ela de tal forma que o problema de um seja o problema de todos, e todos em conjunto devem tentar resolvê-lo. E todo esse envolvimento não está limitado aos funcionários, mas deve abranger também a própria diretoria da empresa.

A otimização de tecnologias do tipo $\mathrm{CAE} / \mathrm{CAD} / \mathrm{CAM}$, por exemplo, está baseada na capacidade adminis-
As informações importantes fluem de maneira organizada e participativa entre os vários segmentos, sem a ocorrência de monopolização por esse ou aquele departamento. Normalmente quando se pensa em qualidade, pensa-se logo no setor de fabricação de um produto. É comum se ouvir: "tal produto foi fabricado sem qualidade!". Isto pode não ser verdade. A falta de qualidade do produto pode ser oriunda do projeto, da engenharia do produto ou do ferramental. Uma peça deve nascer com qualidade, o que só é possível se houver integração de informações entre os diversos departamentos responsáveis pela sua criação e sua fabricação. É importante que as condições de fabricação de um novo produto sejam conhecidas antes da confecção dos moldes ou até mesmo durante a etapa de design, pois quanto mais tarde for realizada uma modificação no projeto do produto, maior se torna seu custo.

A utilização inadequada de técnicas revolucionárias de gestão,

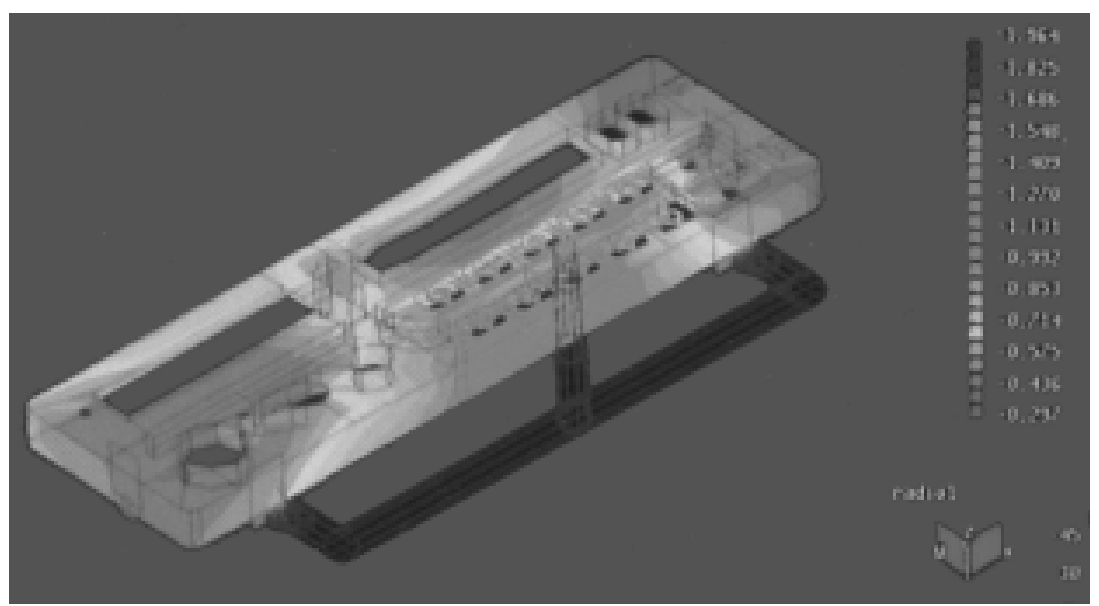

trativa da empresa gerenciar técnicas como a engenharia simultânea, onde o planejamento de desenvolvimento de um novo produto é realizado com a participação simultânea de pessoal dos setores de marketing, da engenharia de produto, da ferramentaria e da produção. como a reengenharia, muitas vezes tem sido prejudicial à modernização tecnológica. O ímpeto de cortar despesas e otimizar o faturamento tem levado ao corte do patrimônio tecnológico, tal como o enxugamento do departamento de engenharia. A recuperação da 
capacitação pessoal deste setor só ocorre a médio e longo prazo. Dependendo como o processo de reengenharia é realizado pela empresa, pode colocá-la numa situação insustentável de sobrevivência. Em empresas de caráter familiar, por exemplo, com forte ênfase paternalista, não é recomendável dispensar os profissionais que nela trabalham desde o início de suas atividades. Toda a experiência adquirida por esse corpo técnico deve ser dirigida para uma nova capacitação tecnológica, através de treinamentos adequados. A empresa não pertence somente ao empresário mas também ao mercado. Seu patrimônio, além das máquinas e da tecnologia, é também o conhecimento integrado entre os vários setores da empresa.

\section{DISPONIBILIDADES TECNOLÓGICAS}

O setor de transformação de plásticos necessita de técnicas inovadoras para otimizar seus produtos moldados. Existe, entretanto, uma atitude conservadora por parte de algumas empresas, que resistem ao emprego de novas tecnologias, em especial às técnicas computacionais modernas. Muitos empresários ainda acreditam que a experiência humana de projeto, de ferramentaria e de operação são suficientes para promover as inovações necessárias, o que não é verdade dentro dos padrões atuais de competitividade originados pela globalização econômica, cujo impacto nas empresas brasileiras pode ser facilmente verificado. Contrapomos a essa argumentação os benefícios diretos das novas tecnologias. Apresentamos a seguir algumas das técnicas mais avançadas de projeto e de fabricação na área de plásticos moldados, cujo conhecimento é necessário para se investir de maneira correta.

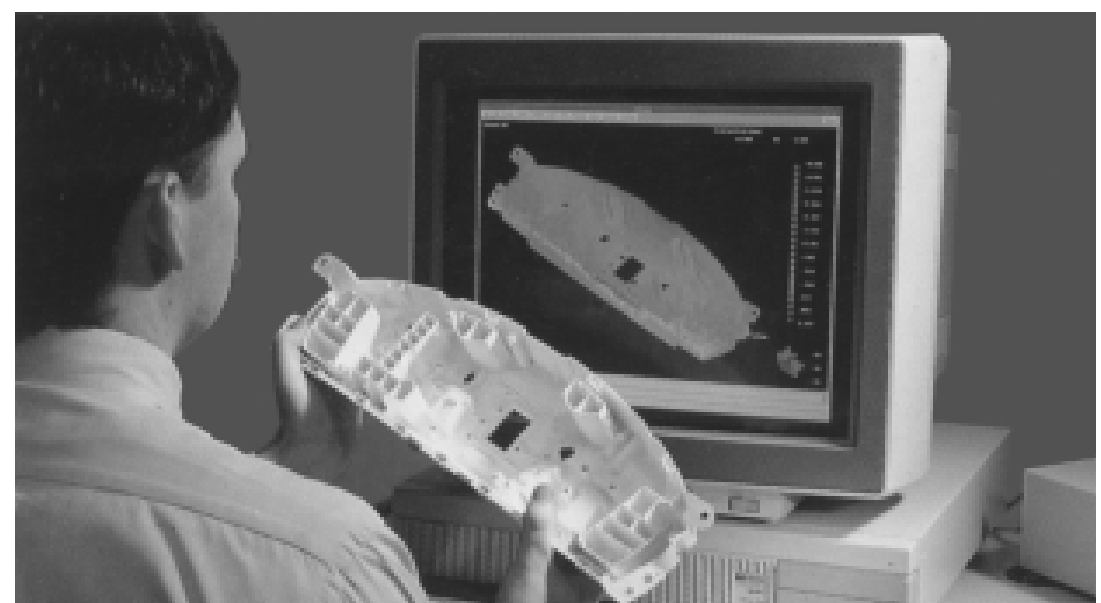

\section{CAE/CAD/CAM}

CAE (Computer Aided Engineering), CAD (Computer Aided Design) e CAM (Computer Aided Manufacturing) são técnicas computacionais utilizadas no projeto de uma peça moldada em plástico, constituídas por um conjunto específico de softwares que auxiliam desde a concepção do produto, passando pela confecção do molde/ matriz até a simulação da fabricação da peça. O sistema CAD é utilizado para definir o design da peça incluindo além do desenho, as dimensões, as características dos materiais constituintes da peça, as tolerâncias dimensionais e a melhor técnica de moldagem. $\mathrm{O}$ aspecto tridimensional da peça projetada é então transformado em superfícies definidas matematicamente pelo software e todas as informações obtidas serão utilizadas pelo sistema CAM para confeccionar a cavidade do molde empregado na fabricação da peça. O CAM transmite as informações para uma máquina de comando numérico, que por sua vez usina a cavidade do molde de maneira exata, dentro das tolerâncias estabelecidas. O sistema CAE tem como objetivo a simulação da fabricação da peça no molde projetado pelo sistema conjunto CAD/CAM. Alguns softwares CAE aplicados às cavidades projetadas proporcionam todas as informações para seu preenchimento. Assim, antes de confeccionar efetivamente o molde pode-se testálo, estabelecendo os perfis de pressão, de temperatura, de fluxo, etc. O benefício desta técnica é a definição no computador das melhores condições para construir uma peça em plástico, de forma que ela seja executada da maneira mais adequada dentro dos aspectos de engenharia. Na fabricação de uma peça moldada por injeção, por exemplo, sabe-se que podem existir linhas de solda durante o preenchimento da cavidade que quase sempre geram regiões mais fracas, acarretando menor resistência mecânica e até mesmo dificuldades funcionais para a peça. Utilizando o sistema CAE é possível deslocar a linha de solda para outra região, onde não comprometa o desempenho. Além disso é possível reduzir a espessura, em função da simulação de esforços mecânicos impostos pelo CAE, otimizando o balanço de material distribuído na peça. Todas estas alternativas proporcionam um controle antecipado da qualidade da peça, projetando o molde em função do processo. As três técnicas CAE/CAD/CAM funcionam integradas e é possível projetar um produto visualizando desde sua concepção até a simulação de sua fa- 
bricação. Antigamente se fazia o modelo de um produto em madeira ou massa plástica. Após ser aprovado pelo marketing, esse modelo tinha suas dimensões desenhadas tecnicamente e passava para o setor de ferramentaria. A confecção do molde era então realizada através de uma máquina convencional ou de comando numérico. O teste de preenchimento e de fabricação eram realizados após a confecção do molde. Além dos riscos técnicos relativos à qualidade da peça, $o$ lançamento do produto através deste procedimento convencional levava em média um ano, tempo que pode ser reduzido em até $1 / 3 \mathrm{com}$ o uso de técnicas CAE/CAD/CAM.

\section{Prototipagem Rápida}

Como mencionado no parágrafo anterior, o projeto de lançamento de uma peça em plástico pelo sistema convencional passa pela modelagem da peça em madeira ou massa plástica, num processo que exige a participação de um modelador, num procedimento artesanal. As técnicas computacionais têm permitido que a prototipagem seja realizada com precisão técnica em algumas horas, tempo bem menor que o convencional, que podia chegar a 45 dias. O projeto de uma peça no sistema CAD pode ser transferido para um equipamento computacional que comanda a fabricação do protótipo em resina. A prototipagem rápida conta com várias técnicas específicas. A estereolitografia, uma das mais eficientes, utiliza o raio laser para polimerizar uma resina fotocurável líquida. $\mathrm{O}$ raio laser caminha na superfície da resina líquida através do comando de um software no qual existe a imagem do protótipo. A cura da resina no formato imposto pela fi- gura desenhada por ele transformase em protótipo, copiando fielmente o desenho que foi inicialmente projetado pelo CAD. A prototipagem rápida no Brasil possui ainda uma relação custo/benefício relativamente elevada para a confecção de protótipos de baixa complexidade, como no caso de peças simples o que, todavia, não inviabiliza sua utilização nos setores automobilístico, eletroeletrônico, metal-mecânico, etc., cuja permanência dos produtos no mercado é relativamente curta.

\section{Digitalização Tridimensional}

Esta técnica permite fazer o caminho inverso da prototipagem, na medida em que possibilita levar o desenho de uma peça para o computador e obter sua forma eletrônica que irá permitir depois a prototipagem rápida. No Brasil esta técnica é muito útil em projetos de veículos, onde o estilo do carro é transformado em protótipo de madeira ou massa plástica, em tamanho original, sem que se tenha no computador a superfície matemática correspondente. As diversas partes, como pára-lamas, pára-choques, etc., não são individualizadas nestes protótipos, que precisam ser escaneados eletronicamente através de um equipamento especial, para a criação do desenho tridimensional e da superfície matemática. A partir daí as partes de interesse são seccionadas e manipuladas isoladamente através de um processo de simulação. Neste estágio cada peça pode ser abordada de maneira independente pelo sistema CAE/CAD/CAM.

Às vezes pode haver o caminho inverso. Uma empresa pode desenhar ou copiar uma peça, sem ter a superfície matemática para jogá-la de forma tridimensional no compu- tador. A forma será digitalizada eletronicamente e o arquivo gerado pode ser utilizado nos sistemas CAE/CAD/CAM para fazer a peça com economia e precisão.

\section{Injeção a Gás durante a Moldagem}

Simulada em sistemas CAE/ CAD/CAM, esta técnica apresenta a grande vantagem de se fabricar uma peça estrutural oca por dentro. Atende-se às especificações desejadas porém há menor consumo de matéria-prima e a peça torna-se mais leve. O processo possui o seguinte princípio: a cavidade do molde é parcialmente preenchida com o plástico e então o gás é injetado através de canais estrategicamente distribuídos. Neste estágio o plástico expande e preenche o espaço restante da cavidade. Assim uma parte da peça é preenchida com plástico e a outra com gás. O projeto deste tipo de cavidade é complexo e exige um procedimento de simulação computacional. Se não houver a simulação corre-se um risco muito grande do gás furar a bolha de plástico durante a expansão na cavidade, danificando a peça. $O$ custo da confecção de moldes através dos processos convencionais, por tentativas e erros, tornaria totalmente inviável a utilização desta tecnologia.

\section{A PLENA UTILIZAÇÃO DAS NOVAS TECNOLOGIAS}

Uma parte significativa das empresas do setor de transformação demonstra uma certa relutância em adquirir técnicas ou equipamentos sofisticados para a fabricação de peças em plástico. A causa principal de tal receio é a escassez de pessoal técnico da empresa treinado para operá-los. Uma das 
alternativas disponíveis para solucionar esse impasse seria a contratação de serviços, através da terceirização, para treinar o pessoal da fábrica na tecnologia adquirida. No Brasil este tipo de alternativa tem se mostrado eficiente, observando-se uma tendência acentuada de abertura de pequenas empresas constituídas de duas ou três pessoas altamente especializadas em tecnologias de ponta como CAE/CAD/CAM, projetos de molde usando bicos quentes, digitalização, etc. É necessário difundir mais os recursos existentes, alertando-se as empresas para a necessidade de cobrança da qualidade do treinamento de quem os está fornecendo, bem como da qualidade dos manuais que estão sendo fornecidos. Esses são dois pontos extremamente críticos, por se tratar de tecnologias desenvolvidas no exterior e comercializadas por representantes que não somente devem conhecer muito bem o produto como também ter condições de oferecer um bom suporte.

Outro aspecto que deve ser observado com cuidado é a utilização plena da tecnologia ou equipamento adquirido. $\mathrm{O}$ potencial de utilização deve ser o máximo possível. $\mathrm{O}$ pessoal técnico responsável pela operação dos equipamentos e manipulação das técnicas deve constantemente ser reciclado para não subutilizar as inovações tecnológicas adquiridas. É bastante comum o funcionário principiante selecionar um número limitado de comandos para utilização no dia a dia. Se algum tempo após o aprendizado inicial forem realizados treinamentos de reciclagem, ele assimilará mais facilmente os comandos avançados e poderá utilizar plenamente os recursos do pacote adquirido. $\mathrm{O}$ treinamento continuado deve ser um cuidado a ser tomado para que a empresa usufrua com máxima eficiên- cia da modernização tecnológica, não se esquecendo de que seu oferecimento depende tanto do fornecedor quanto do usuário.

\section{A VIABILIZAÇÃO DOS RECURSOS DISPONIVEIS}

A capacitação técnica é um dos mais importantes requisitos para a modernização do parque industrial brasileiro, sobretudo do setor de transformação de plásticos. Os financiamentos e os incentivos fiscais são igualmente relevantes, todavia dependem da vontade política dos órgãos governamentais, o que faz com que a atualização tecnológica resulte basicamente da iniciativa das empresas.

O apoio técnico necessário para a modernização poderá ser conseguido através de uma interação eficiente dos diversos segmentos da indústria com instituições e centros de pesquisa. No que se refere à formação de recursos humanos, o Brasil já possui um potencial razoável. As escolas técnicas SENAI, TUPI, etc, que formam profissionais para o setor de transformação de plástico, dentre outros, estão se empenhando na atualização tecnológica de seus alunos. Algumas universidades mantêm cursos nas áreas de engenharia e de química que oferecem uma formação especializada em polímeros. Existem também vários cursos de pós-graduação, a nível de mestrado e/ou doutorado que propiciam a formação de recursos humanos nessa área. Há necessidade, porém, de se priorizar os investimentos nos Centros de Excelência já consolidados para ampliar o número de profissionais especializados e tecnologicamente atualizados.

As empresas, por sua vez, devem tentar se agrupar e formar cooperativas, tanto para dar maior apoio aos Centros já existentes, como para criar outros pólos que lhes dêem suporte nos mais variados setores, seja de técnicas de gestão, materiais, processos de montagem de equipamentos, etc. Além de minimizar os custos, que seriam rateados entre os participantes, a iniciativa otimizaria os esforços e serviria de contrapartida para se exigir do governo os incentivos necessários à manutenção desses centros de excelência, que se constituem hoje num dos mais importantes instrumentos para que as empresas tenham a agilidade e a velocidade de atualização tecnológica exigidas pelo mercado atual e do futuro.

\section{A PROPOSTA PARA CRIAÇÃO DO PÓLO TECNOLÓGICO-INDUSTRIAL}

Fiel aos objetivos básicos do Instituto de tornar as indústrias do plástico competitivas a nível global, de acordo com as mais modernas tecnologias e técnicas de gestão, o INP juntamente com a ABIMAQ estão mobilizando a comunidade visando a criação do Pólo Tecnológico-Industrial de Design, Modelação, Matrizaria e Ferramentaria. Segundo José Simanto Netto, esse Pólo deverá promover o desenvolvimento de produtos e processos que antecedem a produção industrial de produtos moldados em plásticos, borrachas e metais, através da implantação de um Centro Tecnológico, em torno do qual se reunirão em um único local os fabricantes de moldes e matrizes, assistidos por toda uma infra-estrutura de serviços.

Ao disponibilizar os serviços de Engenharia de Produto, Formação e Qualidade para toda a comunidade transformadora de plástico, representada por designers, transformadores, fabricantes de moldes, etc. o design do produto é concebido em sua forma mais abrangente, 
em tudo o que antecede a fase da plena produção, ou seja, a engenharia simultânea, requerida pela QS 9000, a norma específica da indústria automotiva. Com isso pretende-se oferecer às empresas os mecanismos necessários para sua atualização tecnológica em base globalmente competitiva, otimizando fatores de competição como: - melhor qualidade; - redução de custos de fabricação; - redução de tempos (desenvolvimento do produto, preparo de máquina, ciclo de produção e atendimento de pedidos); maior flexibilidade; - inovação (agregação de valor ao cliente).

Pretende-se construir o Pólo em Sumaré, em terreno doado pela Villares, com infra-estrutura e incentivos da Prefeitura daquela cidade e do Estado. A estrutura básica prevê uma área onde as empresas poderão se instalar sob a forma de condomínio e outra para o Centro Tecnológico. A localização é bastante estratégica, próxi- ma à UNICAMP, ao aeroporto de Campinas e à cidade de Paulínia.

Os recursos financeiros para o investimento poderão advir da Comunidade Européia, BNDES, Lei 8661 (a partir da dedução de até $8 \%$ do IR a pagar das petroquímicas, para financiar a fundo perdido projetos cooperativos de P\&D) e outras fontes. As holdings petroquímicas, em especial, poderiam avalizar eventual parte com retorno. Quanto à transferência de tecnologia para o Centro Tecnológico, está em andamento uma proposta da ASCAMM - Associación Catalana d'Empreses Constructores de Motles y Matrices, de Barcelona.

A proposta vem recebendo o apoio dos mais variados setores, tendo sido convidadas a compor a Coordenação Executiva do Projeto as seguintes entidades: ABIMAQ/ DNFM, INP, ABIPLAST, ABIQUIM /SIRESP, FINEP/BNDES, MICT, MCT, Secretaria Estadual da Ciên- cia, Tecnologia e Desenvolvimento do Estado de São Paulo, IBQP - Instituto Brasileiro da Qualidade e da Produtividade; ABNT, INMETRO, Villares Metals, Prefeitura Municipal de Sumaré, SENAI, FIESP, CNI e IPT. A iniciativa do INP e da ABIMAQ de criação de um Pólo Tecnológico vem de encontro às mais modernas tendências mundiais, na medida em que valoriza os mecanismos que tornam setores e/ou países competitivos, ao invés de apenas empresas competitivas.

Em função dos benefícios que poderão advir não apenas para a comunidade industrial em si, mas para todo o país, Polímeros: Ciência e Tecnologia continuará divulgando em suas próximas edições os assuntos relacionados ao Pólo Tecnológico-Industrial em fase de criação, bem como as atividades dos outros Centros de Excelência que prestam serviços na área de polímeros.

Matéria elaborada pelo Prof. Elias Hage Jr. (UFSCar/DEMa) com a colaboração de Fátima S. Cordebello (ABPol) 